\title{
ON THE ROLE OF VIGILANCE IN THE INTERPRETATION OF PUNS
}

Humans are vigilant against deception and misinterpretation thanks to a set of cognitive mechanisms that monitor their interlocutors' benevolence, credibility, competence and preferences, as well as the plausibility and acceptability of the interpretative hypotheses constructed. This paper explores the role of these mechanisms in the comprehension of puns. Through purposeful ambiguity, these bias the audience to an interpretation which, despite initially receiving some credibility, must be dismissed in order for the audience to arrive at a less salient interpretation. In doing so, this paper suggests an approach to their comprehension that differs from previous relevance-theoretic ones, which regard optimal relevance as the criterion determining the acceptability of interpretative hypotheses. Vigilance mechanisms are here argued to be essential for the audience to consider additional interpretative hypotheses, as these mechanisms alert the audience to the punster's jocular intention, which surfaces in the production of a text amenable to reinterpretation. They also trigger a sophisticated processing strategy that encourages the audience to backtrack in order to detect the reinterpretable part of the text. This involves metarepresentation, as the audience need to attribute to the communicator the intention to transmit a different message.

\section{Introduction}

Puns have constantly intrigued scholars, who have approached them from different angles and explored issues like their types, usage and functions in certain contexts, or how they are processed (e.g., Hartmann and Stock 1972; Norrick 1984; Raskin 1985; Attardo 1990, 1993, 1994; McArthur 1992; Tanaka 1992, 1994; Crystal 1995; Bussman 1996; Yus Ramos 2003; Chovanec 2005; Kosińska 2005; Dynel 2010; Díaz Pérez 2012; Solska 2012a, 2012b, 2012c). Much effort has been dedicated to unravelling how punsters contrive a linguistic puzzle, which on some occasions the audience almost solve after dismissing an interpretation initially entertained, while on other occasions they cannot because of failure to select a particular interpretation. Researchers have suggested a number of answers about why a first interpretation is rejected and a new one searched for. Within relevance-theoretic pragmatics (Sperber and Wilson 1995; Wilson and Sperber 2004) - which this paper endorses - it has been claimed that considerations of optimal relevance lead the audience to engage in that search (Tanaka 1994; Solska 2012a, 2012b).

Although expectations of relevance drive the comprehension module throughout processing, they cannot be the sole factor whereby the audience ultimately accept 
interpretative hypotheses (Wilson 2011; Padilla Cruz 2012; Mazzarella 2013). Research in psychology and pragmatics has shown that for hearers to opt for a specific interpretation they must trust their interlocutors and the information they supply (Mascaro and Sperber 2009; Sperber et al. 2010). This requires theory of mind abilities that enable individuals to understand whether the communicator believes what she $^{1}$ says is true - first-order mental states - or what the communicator knows the audience know, what the communicator intends the audience to believe or what the communicator believes the audience believe - secondorder mental states (Leekam 1991; Happé 1994; Sullivan et al. 1995; Sullivan et al. 2003; Wilson 2013).

This paper will regard puns as a type of false texts (Leekam 1991) inasmuch as the punster, though not communicating proper falsehoods, intentionally seeks to (mis)lead the audience through ambiguity to an interpretation which, though seemingly plausible and relevant, is unintended or incorrect. ${ }^{2}$ As in other forms of humour like some types of jokes, punsters fool the audience into granting some plausibility to that interpretation, but the audience subsequently need to detect its weirdness or illogicalness for a pun to achieve a variety of humorous, aesthetic, intellectual and communicative effects (Yus Ramos 2003, 2008; Padilla Cruz 2012). As opposed to lies, wherein the speaker does not intend to be truthful and knows that she is saying something false, in puns the communicator does not seek to deceive, but to be disbelieved (Leekam 1991; Sullivan et al. 2003): she expects the audience not to believe the first output of disambiguation as intended. The questions that arise are (i) why the audience disbelieve that output, and (ii) if there is a cognitive mechanism responsible for this.

This paper will suggest that the audience may detect inadequate interpretations thanks to a suite of mechanisms checking our interlocutors' benevolence, credibility, competence and preferences, the reliability of communication and the plausibility and acceptability of interpretative hypotheses (Sperber et al. 2010; Padilla Cruz 2012, 2013a; Mazzarella 2013). 
Some characteristics of puns and/or the punster's behaviour may (over-)activate those mechanisms, which then alert to the punster's playful attitude. A subset of those mechanisms may also cause backtracking and discover flaws, errors and/or alternatives in disambiguation and trigger a sophisticated processing strategy that results in a reanalysis of the pun in order to look for the interpretation that the audience think that the punster might have prevented them from reaching more directly and easily (Sperber 1994; Wilson 1999). This search involves mindreading, as the audience need to attribute to the punster the intention to communicate another message.

\section{Puns}

The extant literature underlines the wittiness and humorous potential of puns due to a play on lexical meaning and/or the similarity between words semantically or etymologically unrelated (Hartmann and Stock 1972; McArthur 1992; Crystal 1995; Bussman 1996). Puns are ostensive acts of communication - intentional communication wherein the speaker has an informative intention to communicate a message (Sperber and Wilson 1995) - which exploit the phonetic similarity of a particular linguistic string with another in order to create purposeful ambiguity and a certain indecision in the audience as to the message communicated. Upon solving such ambiguity, the latter cannot but assign different interpretations to that string (Kosińska 2005: 76-77). To put it differently, the audience construct a first interpretative hypothesis which, though compatible with the linguistically encoded content, turns out unsuitable because it is not perceived as the intended interpretation. In other cases, the first interpretative hypothesis is as equally plausible as another interpretation, so the audience cannot decide upon the actual intended one. This causes them to either construct another interpretative hypothesis or refine the constructed one (Wilson 1993; Solska 2008). 
Classifications of puns stress the role of a pivotal element causing backtracking, reanalysis and re-interpretation: the connector (Attardo 1994; Tanaka 1994; Yus Ramos 2003; Dynel 2010). Despite the subtypes differentiated, in the interest of simplicity puns will be broadly divided here into those resulting in one interpretation, namely single-retention puns (1-4), and those yielding two, namely double-retention puns (5-8) (Dynel 2010):

(1) When I see the first strand of grey hair, I'll certainly die.

(2) I'm not a complete idiot. Several parts are missing.

(3) I don't suffer from insanity. I enjoy every minute of it.

(4) I'm on a seafood diet. Every time I see food, I eat it.

(5) There was a sign on the lawn at the drug re-hab centre that said 'Keep off the Grass'.

(6) Change is inevitable... except for the vending machine.

(7) I'm up and down like a toilet at a mixed party.

(8) I play Cinderella tennis. I don't quite get to the ball.

Note, however, that this twofold distinction is simplistic, idealistic and troublesome, as there seems to be a continuum of cases ranging from those in which ambiguity is hardly solved to those in which it is almost, but not completely, solved. If it were, puns would lose their essence and humorous potential (Guiraud 1976; Attardo 1994). Indeed, what makes a particular utterance/text be a pun is the feeling that it might have competing interpretations.

Punsters move to a non-bona-fide mode of communication (Attardo 1990, 1993; Raskin 1995), or to a humorous frame (Yamaguchi 1988), which the audience can activate thanks to their textual features and the (non-)linguistic elements accompanying puns (Garcés Conejos 2003; Kosińska 2005). These can be mentally represented as encyclopaedic or cultural 
assumptions which are fed into inferential processes and significantly determine interpretation (Sperber 1996; Unger 2001; more on this below). That mode of communication surfaces in a verbal trap wherewith punsters seek to make the audience reach an inappropriate interpretation on the basis of considerations of accessibility and effort. Upon finding that interpretation optimally relevant the audience may believe it to be the intended one.

In order to device that trap, punsters take advantage of the pragmatic ambivalence of words and strings that resemble others and, hence, may have a variety of interpretations. They also rely on rough estimates about the audience's interpretive abilities and the cognitive procedures they may carry out. Punsters, so to say, can "read the audience's minds" (Apperly 2012) and anticipate their beliefs and the interpretative routes they are likely to follow. To some extent, punsters foresee how the audience will disambiguate and assign a specific meaning to the ambivalent or 'troublesome' string, as well as the contextual or linguistic information the audience will exploit (Carston 2002; Wilson and Sperber 2004; Yus Ramos 2003, 2008). This provides punsters with some awareness of which interpretation(s) will become more salient in particular contexts (Giora 1997) and of its/their costliness (Yus Ramos 2003, 2008).

Funniness or enjoyability arise because the audience notice the implausibility or inadequacy of a first interpretation, realise that they were surreptitiously (mis)led to it, cancel and discard it (McGhee 1972; Attardo 1993). They then engage in further processing so as to construct (at least) another feasible, but maybe better, interpretation from which they can obtain the cognitive gain that compensates for the effort invested, as the first interpretation is not considered relevant enough (Solska 2012a, 2012b). But what makes the audience suspect of the implausibility of an interpretation and reanalyse a pun? Why do the audience feel that they could obtain more cognitive gain from a distinct interpretation? And is there anything that prompts them to search for that interpretation? 


\section{Interpreting puns}

The interpretation of puns follows the relevance-driven comprehension procedure applicable to ostensive acts of communication. In it, hearers follow the path requiring the least mental effort when carrying out a process of mutual parallel adjustment of both explicit and implicit content - i.e. when parsing, disambiguating constituents, adjusting concepts, constructing speech-act or propositional-attitude descriptions, supplying necessary implicated premises and drawing implicated conclusions - and yielding the most satisfactory amount of cognitive effects in order to construct interpretative hypotheses (Wilson 1999; Carston 2002; Wilson and Sperber 2004). Upon hearers' feeling that their expectations of relevance are satisfied, they halt the process and may regard an interpretative hypothesis as intended (Sperber and Wilson 1995; Wilson and Sperber 2004). But hearers believe that one particular interpretative hypothesis is the intended one if they assume that the speaker is competent - i.e., knowledgeable in a topic or field and capable of using the linguistic system efficiently depending on her expressive abilities and preferences - and benevolent - i.e., not deceptive (Sperber 1994).

The crux of puns resides in ambiguity. Inaccurate correspondences between naturallanguage words/strings and mental concepts contribute to the so-called garden-path effect (Wilson 1993; Solska 2008). On the one hand, some concepts do not only map onto one single word, but onto different ones; on the other hand, a natural language may only have one word for diverse concepts, or that some concepts can only be effable through complex linguistic structures and not simply words (Wilson and Sperber 1993; Sperber and Wilson 1997; Wilson 1997; Carston 2002). Ambiguity may be due to homonymy, polysemy, homophony, homography, paronymy, or on a combination of these with other figures of speech like metaphor (Bucaria 2004; Solska 2012a, 2012b, 2012c), thanks to similarities, 
intersections or overlapping between the information contained in any of the three types of entries of the concepts encoded:

a) The logical entry, or the finite and relatively stable set of defining properties of a concept specifying its logical relations with other concepts (Sperber and Wilson 1995: 92).

b) The encyclopaedic entry, which includes information about the extension and/or denotation of the concept and varied assumptions about personal experience. Organised in frames, schemas and scripts, the content of this entry varies across individuals and times. Storage and access to its information depends on factors such as recentness, saliency or easiness of accessibility of items (Sperber and Wilson 1995: 93).

c) The lexical entry, which includes phonetic and grammatical properties of the word connected with a concept (Carston 2002: 321-322).

Hearers normally seem to succeed at disambiguation thanks to the information in these entries, neighbouring expressions and/or contextual sources such as intonation, paralanguage or cultural knowledge. If hearers are uncertain about the best or expected outcome, they may choose the most salient or less costly meaning, negotiate meaning with their interlocutor (if possible) or simply refrain from solving the ambiguity, unless it impedes communication. However, puns are purposely devised to puzzle the audience (Attardo 1994; Tanaka 1994; Yus Ramos 2003; Dynel 2010): the communicator's competence and linguistic abilities enable her to present a tricky string which deliberately confuses or leads the audience astray, so the communicator cannot be said to behave benevolently.

According to Solska (2012a: 172-173, 2012b: 397-403), in puns based on homonymy and polysemy, the audience hesitate because the concepts involved share the same lexical entry, but their logical entries differ and give access to distinct encyclopaedic information: 
(5) There was a sign on the lawn at the drug re-hab centre that said 'Keep off the Grass'.

Puns relying on the juxtaposition of metaphorical or idiomatic interpretations to literal interpretations cause indecision because the concepts involved, though sharing their lexical entries, slightly differ with regards to the content of their logical and encyclopaedic entries:

(9) Burning Questions on Tunnel Safety Unanswered.

The audience's difficulties to work out puns exploiting homography (10) and homography (11) stem from the fact that a same graphic or phonological string activates two concepts with distinct lexical, logical and encyclopaedic entries:

(10) Having demonstrated his shooting prowess, the king gave the archer a little bow.

(11)A Steak in the market. [Headline of a newspaper article on two big meat producers agreeing to merge]

Finally, puns contingent on imperfect homophony and paronymy puzzle the audience because the concepts involved only share a fragment of the phonetic form of the natural language word or expressions associated with them:

(12) Silent Blight. [Headline of a newspaper article on the incidence of sore throats among teachers] 
When barely solved, ambiguity causes an oscillating effect (Dynel 2010; Solska 2012a, 2012b). Contextual material gives the audience reason to suspect that the ambiguous string may have a different interpretation from which more cognitive gain can be obtained. Unfortunately, upon reaching that interpretation, the audience may not find it more relevant than the one previously constructed (Solska 2012a: 178). This makes the audience indecisive about which interpretation to opt for and "the two meanings of the pivotal expression get activated only to clash with each other [...] since the contextual assumptions available to the hearer do not give him reason to abandon either" (Solska 2012c: 6). This is illustrated as follows:

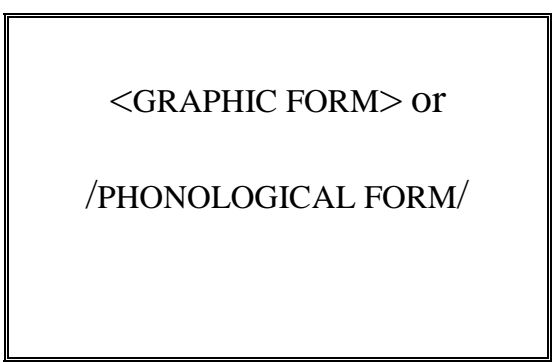

OSTENSIVE SIGNAL

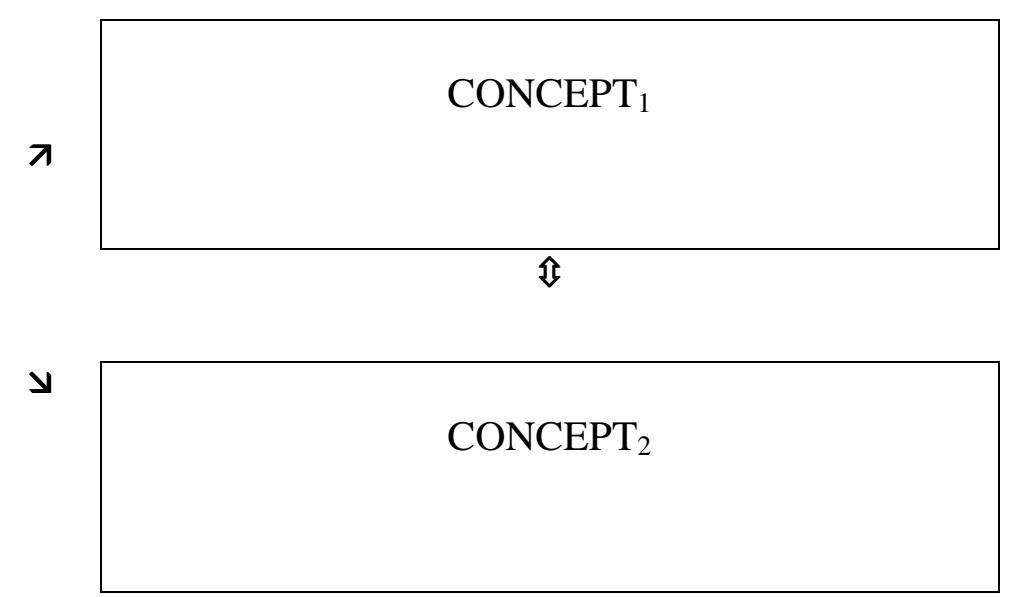

CONCEPTS CONVEYED

Figure 1: Oscillating effect in double-retention puns (Solska 2012c: 7).

If ambiguity is almost resolved, the audience may not waver. Nevertheless, the illogical or weird meaning does not seem to be totally abandoned, but "lingers on in the hearer's mind and provides the necessary counterpoise for the fully viable meaning" (Solska 2012c: 7). The following figure illustrates this: 


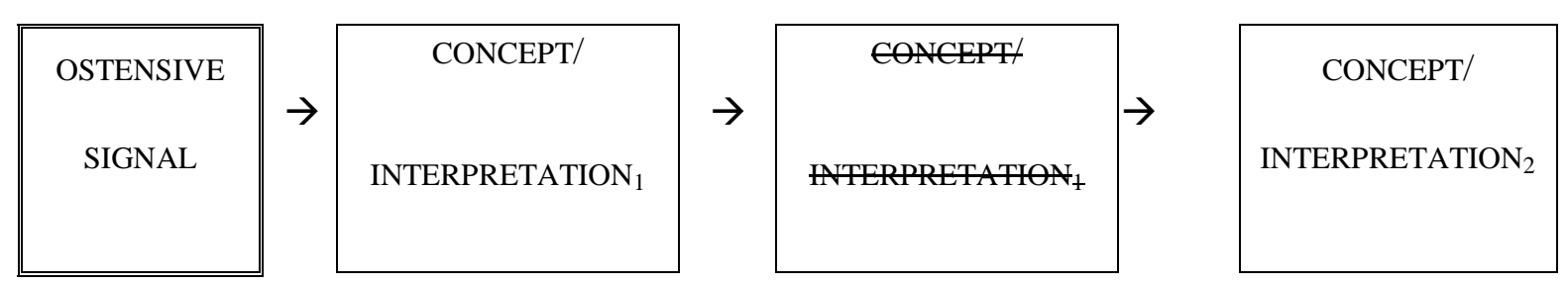

Figure 2: Interpretation process in single-retention puns (Solska 2012c: 6)

Expectations of cognitive reward pervade comprehension and seem to represent the “"acceptability criterion' that an interpretative hypothesis needs to satisfy in order to be retained and attributed to the communicator" (Mazzarella 2013: 22). In single-retention puns a first interpretation does not satisfy this criterion, while in double-retention puns the audience cannot select one because the two interpretations appear equally relevant. However, oscillating between two interpretations, or retaining a rejected one, detracts from optimal relevance (Sperber and Wilson 1995; Wilson and Sperber 2004) because further, maybe worthless, effort is needed in order to "formulate not one but two (or more) propositions, each of them with its own set of truth conditions and each containing one of the concepts made available by the punning expression" (Solska 2012a: 177).

Optimal relevance cannot be a final acceptability criterion (Mazzarella 2013: 27); acceptability of interpretations must depend on other factors, such as mental states - beliefs, desires and intentions, among them the communicator's informative intention - attributed to other individuals. The human mind is equipped with some mechanisms that work in parallel with the comprehension module by assessing the acceptability and believability of its output (Sperber et al. 2010; Padilla Cruz 2012, 2013a, 2013b; Mazzarella 2013). Those mechanisms monitor the communicator's mental states and detect if she is not benevolent or seeks to fool the hearer into regarding an interpretative hypothesis as intended (Leekam 1991; Happé 1994; Sullivan et al. 1995; Sullivan et al. 2003). Arguably, information about the speaker's mental 
states is fuelled into inferential processes as contextual assumptions made manifest by, for instance, physical co-presence (Mazzone 2011, 2013). That information, nonetheless, results from metarepresentational abilities and greatly determines inferential processes (Mazzarella 2013: 28-30). Concerning puns, the said mechanisms, generically labelled vigilance, take information about the speaker's mental states and other information into account and arouse suspicions about the existence of alternative interpretations, so they can enact the search for them.

\section{Vigilance in communication}

A hearer concludes that an interpretation may be intended if:

(i) He trusts the speaker, i.e., he thinks that she is benevolent and does not seek to deceive, mislead or misinform him (Sperber 1994).

(ii) He finds the contextual information he exploits reliable and valid for arriving at that interpretation.

(iii) He considers that he did not make any mistake in the cognitive operations involved in processing.

The hearer may sense that an interpretation, despite its seeming relevance, is inadequate or unwarranted because the speaker could have inadvertently made some expressive mistake or intentionally biased him to it, or because he himself could unknowingly have made an interpretative mistake or used inappropriate information.

Individuals are characterised by an attitude of epistemic trust: the readiness to believe interlocutors and accept what they say as true (Mazzarella 2013: 31; Origgi 2013: 224). Epistemic trust consists of default trust, or the minimal, indispensable confidence allocated to interlocutors, and vigilant trust, operating when processing information. The latter rests on a series of innate mechanisms, emotional dispositions, inherited norms and commitments, as 
well as factors like the informants' age and reputation, previous judgements and experiences of their trustworthiness, or evidence of uncertainty, nervousness, anxiety or some attitudes (Michaelian 2013; Origgi 2013). Vigilant trust causes a critical stance to interlocutors and the information they provide, epistemic vigilance, which leads individuals to check the credibility and reliability of informants and information (Mascaro and Sperber 2009; Sperber et al. 2010: 363). ${ }^{3}$ Epistemic vigilance monitors against one of the risks of communication: deception. It is not a systematic distrust in others, but a critical disposition that avoids blind, naïve and uncritical gullibility.

Epistemic vigilance makes rough estimates about other people's competence/knowledge in some issue or domain and their benevolence/honesty when communicating. It also evaluates the communicator's abilities - i.e., the cognitive skills and capabilities underlying her linguistic performance - and preferences - i.e., goals such as complying with norms dictating register, amount or type of information to dispense, etc. (Mazzarella 2013: 33-35). Accordingly, epistemic vigilance can filter out interpretative hypotheses that should not be accepted as intended because of their incompatibility with the speaker's abilities and preferences. This enables the hearer "to dismiss otherwise relevant interpretations that the speaker would have not been willing [...] to convey" (Mazzarella 2013: 37).

Vigilance mechanisms work at an incredibly fast pace and cope with a vast amount of information, so individuals very rarely take the time to become aware of the factor(s) whereby they trust informants or accept interpretations (Origgi 2013: 223). On some occasions, vigilance is strongly effective and suffices to avoid deception or misinterpretation. On other occasions, it is moderately effective and requires the collaboration of (an)other mechanism(s). Still on other occasions, vigilance is weakly effective and may be overrun or overwhelmed 'defeated', so to say - because it is not dedicated enough effort; hence it may fail to avoid deception and misinterpretation (Michaelian 2013: 42-46). Although the average state of 
vigilance is moderate effectiveness (Sperber 2013: 64), it can be raised by a conscious process wherein individuals interrogate themselves about why they (dis)trust someone or some item of information and inspect the data they rely on (Origgi 2013: 224). Raising vigilance involves (Origgi 2013: 226-227):

a) Intentional awareness of the cultural norms, situational factors, biases and/or emotional reactions influencing how individuals think, i.e., external vigilance.

b) Critically unpacking and scrutinising the interpretative steps they take, beliefs accessed and conclusions drawn so as to unravel why they think in a particular manner, i.e., internal vigilance.

If internal vigilance requires individuals to trace how they interpret what others say in a particular manner, vigilance mechanisms could be said to have a specialised subcomponent that targets the hearer's interpretative skills and surveys how interpretative hypotheses are constructed by checking if they are error-free. Since internal vigilance safeguards hearers from interpretative mistakes conducive to misunderstanding, it could be dubbed hermeneutical vigilance (Padilla Cruz 2012, 2013a, 2013b, 2014). As part of the cluster of vigilance mechanisms, hermeneutical vigilance assists those mechanisms by checking the plausibility and acceptability of interpretative hypotheses. As Mazzarella (2013: 32) aptly puts it, "[...] the acceptability issue clearly precedes the believability issue: the interpreter needs to know what the intended interpretation is before he can decide whether to believe it or not".

Misunderstanding may sometimes stem from temporary faults in the speaker's pragmatic abilities owing to absentmindedness, tiredness, nervousness, etc., which impact the formulation of utterances. Also, due to inadequate competence level in the language wherewith she communicates, the speaker may be unaware of conventions having a bearing on the meaning of some expressions or sociopragmatic norms regulating linguistic behaviour. 
However, on other occasions it is the hearer that is to blame for misunderstanding because of his interpretative errors, i.e., he does not perform competently at some of the steps in mutual parallel adjustment (Padilla Cruz 2013a, 2013b). Hermeneutical vigilance incites hearers not to uncritically accept interpretations, but to question how and why they arrive at them. By monitoring the interpretative routes followed and the contextual information exploited when adjusting explicit and implicit import, hermeneutical vigilance checks the feasibility and acceptability of the interpretations of utterances hearers construct or fragments therein clauses, phrases, words, morphemes or even sounds.

Like other forms of humour, puns are intentionally ambiguous texts produced by a communicator who is not only perfectly competent and linguistically skilled, but also capable of predicting how the audience might interpret them. Vigilance must play an important role in their interpretation by alerting the audience to an interpretation that cannot be trusted as intended and triggering the search for (an) additional less salient interpretation(s).

\section{Vigilance and puns}

On the grounds of previous experiences, hearers may automatically trust their interlocutors and the information they communicate, so they do not need to check if epistemic vigilance fulfils its functions. In fact, monitoring their interlocutors' benevolence, competence, abilities and preferences requires a great amount of cognitive effort that hearers may not always be willing to invest (Mazzarella 2013; Origgi 2013). ${ }^{4}$ Just in the same way that individuals presuppose their informants' benevolence and competence, they may also take for granted their own competence and efficiency as hearers. This may lead hearers to unquestioningly accept interpretations constructed through the path of least effort and maximum reward. If hearers do so, they behave as naïvely optimistic individuals (Sperber 1994) and adopt a position of indiscriminate trust (Clément et al. 2004: 361). 
Naïvely optimistic hearers, however, may accept inaccurate or erroneous interpretative hypotheses if these accidentally achieve optimal relevance (Wilson 1999). Their inaccuracy or wrongness may go unnoticed because of insufficient activation of vigilance, which fails to detect the communicator's malevolence or incompetence, or flaws in mutual parallel adjustment. Engaging in naïve optimism explains, for instance, why hearers sometimes miss the humour in some jokes: they accept unintended literal interpretations and those jokes fall flat (Biegajło 2014). Weak or moderate activation of vigilance mechanisms also explains why the audience sometimes fail to grasp double meanings and puns do not achieve their effects: those mechanisms would not caution the audience to contextual features essential for their successful interpretation, such as the medium where they appear (e.g., the advertisement, headline, etc.), accompanying discourse (e.g., co-text, phrases like "do you know the one...?" in canned jokes,) or images, cultural/contextual assumptions or the punster's paralanguage (e.g., a smile, sneer, wink, etc.), which unveil her playfulness.

The activation of epistemic vigilance is raised when the stakes are high, e.g., when hearers interact with individuals considered malevolent or incompetent (Michaelian 2013; Origgi 2013). Likewise, hermeneutical vigilance may be over-activated in situations prone to misunderstanding, i.e., if hearers

- are uncertain about their cognitive abilities because of distraction, nervousness, tiredness, etc., and think that they focus excessively on a small fragment of input without relating it to a broader stretch or, vice versa, they centre on broad fragments of input without duly examining smaller constituents;

- rely excessively on top-down processing and ignore bottom-up processing, or vice versa (Kasper 1984), or

- $\quad$ suspect that their interlocutors cunningly intend to play some verbal trick on them. 
Medium, co-text, paralanguage or encyclopaedic/cultural information are essential for the interpretation of puns: they (over-)activate the cluster of vigilance mechanisms targeting at the communicator's benevolence. These mechanisms can thus caution the audience to the communicator's attempt to dupe them. Vigilance alerts to the punster's 'maliciousness', which is motivated not by an alleged intention to deceive them through false information, but to mislead them to an interpretation which, though seemingly relevant, must be discredited. Indeed, the punster's linguistic competence and abilities enable her to produce an intentionally ambiguous string and predict how the audience will most likely disambiguate it (Yus Ramos 2003, 2008). The factors above also raise the activation of hermeneutical vigilance, which in turn alerts the audience to a potential misinterpretation. Consequently, the audience suspect that the interpretative hypothesis constructed cannot be regarded as intended, despite its reasonableness in other circumstances.

Epistemic and hermeneutical vigilance do not alert to the insufficient relevance of an interpretative hypothesis, as this would involve comparing it to another. Rather, they alert to the implausibility, incorrectness and, hence, unacceptability of a hypothesis constructed, or under construction, which nevertheless seems favoured by the encoded material and considerations of cognitive costliness and benefit. This is what makes the audience wonder why that hypothesis cannot be accepted, suspect the existence of a more viable interpretation, backtrack in order to spot the element(s) they could interpret differently and apply the relevance comprehension procedure again in order to search for another candidate hypothesis compatible with the encoded material, which also yields satisfactory cognitive reward but, most importantly, can be regarded as intended (Solska 2012a). This involves resorting to a more complex processing strategy: sophisticated understanding (Sperber 1994).

A sophisticated hearer is aware of the speaker's malevolence or jocular attitude; otherwise, he would not recognise bad faith, spot lies, grasp some types of humour or double meanings 
in puns. Sophisticated understanding, in fact, moves the hearer to a position of sceptical trust (Clément et al. 2004: 362), whereby he can speculate that a first interpretative hypothesis might not be the best one and realise that the speaker might have surreptitiously biased him to inappropriate parsing, reference assignment, conceptual adjustment or disambiguation. In that position, the hearer conjectures which other relevant interpretation, which the speaker refrains from transmitting, or prevents him from reaching, in a more straightforward and less effortdemanding way, could be acceptable and, ultimately, deserves (more) credibility (Sperber 1994: 194; Wilson 1999: 138). Consequently, the hearer is willing to undertake additional cognitive effort to backtrack and re-analyse input. When interpreting puns, hermeneutical vigilance leads the audience to surmise that a word might have a different meaning and sophisticated understanding enacts the backtracking necessary in order search for it.

In homonymy- and polysemy-based puns like (5), contextual information regarding the fact that the text appears on a sign located in a rehab centre, and not in a park or garden - as this kind of sign usually does (encyclopaedic information) - alerts vigilance mechanisms. Hermeneutical vigilance arouses the suspicion that some of the words may have been intentionally used in order to communicate concepts other than the ones initially activated and instructs the comprehension module to search for concepts that may also be activated by the phonological forms of the words employed. Through sophisticated understanding the comprehension module activates two candidate concepts: GRASS 2 ('marijuana') and $\mathrm{KEEP} \mathrm{OFF}_{2}$ ('resist'), whose logical and encyclopaedic entries differ from those of the concepts initially activated. As a result, the comprehension module re-analyses the text and constructs an alternative interpretation based on those concepts, whose plausibility vigilance then assesses. Since dissuading drug addicts from taking pernicious substances makes sense in the stereotypical context of a rehab centre and this interpretation yields logical and contextual implications concerning, for example, the fact that marijuana is harmful or that its 
consumption should be avoided for rehabilitation to succeed, vigilance may sense that an interpretation based on GRASS 2 and $\mathrm{KEEP} \mathrm{OFF}_{2}$ may result in more cognitive gain in that context. Indeed, the jocularity of that interpretation stems from the fact that the sign in question aims to prevent drug consumption in a rehab centre instead of protecting the grass, which might even suggest that drug addict still take drugs there. Consequently, hermeneutical vigilance will trigger the cancelation of the concepts initially activated, opt for the second ones and accept the interpretation based on them.

In the case of metaphor-based puns like (9), hermeneutical vigilance must alert the audience to the possibility of another narrowing or broadening of the connector (Carston 2002). The noun phrase 'burning questions' in (9) might initially have been interpreted as 'questions needing an urgent discussion', where 'burning' is broadened to BURNING" ('urgent') ${ }^{5}$ due to some emergent property in common with BURNING ('in fire'). The revision of that interpretation through sophisticated understanding may lead the audience to conjecture that the punster might have intended another broadening: the concept BURNING**, meaning 'enthusiastically-/keenly-/intensely-debated', which has (slightly) diverse logical and encyclopaedic entries. If the audience had never broadened 'burning' in this direction, BURNING** would be an occasion-specific or ad hoc concept. An interpretation containing this concept would trigger distinct logical and contextual implications, such as, that much effort and time were devoted to the questions on the tunnel safety or that, despite the enthusiasm or intensity with which they were addressed, no clear conclusion was reached and so their discussion was useless, fruitless or a complete waste of time. On the grounds of the cognitive gain obtained, vigilance would next decide on the worthiness of the interpretation constructed upon the alternative broadening. If vigilance finds it plausible and feels that the gain obtained satisfactorily offsets the effort invested - by provoking humour because of the weirdness of fruitless debate on such an important issue - it will reject the interpretation 
based on the first broadening, which only leads to an interpretation concerning the importance of the questions debated.

An unusual scenario where a king apparently bows to an archer (10) may also activate epistemic vigilance, as it contradicts encyclopaedic knowledge regarding expectable behaviour in front of a monarch. Hermeneutical vigilance facilitates awareness that the punster might cunningly have meant the written form of the word 'bow' to activate a different concept than the one initially activated and triggers sophisticated understanding so as to search for it. The concepts $\mathrm{BOW}_{1}$ and $\mathrm{BOW}_{2}$ share the part of their lexical entries referring to information about written form and grammatical properties - both are nouns - but the rest of their lexical entries - information about pronunciation - differs. In fact, if the word in question was uttered, its ambiguity would disappear and the text would lose its punning effect. Moreover, the contents of their logical and encyclopaedic entries are different. Hermeneutical vigilance will have to determine the plausibility of an interpretation relying on the newly-activated concept on the basis of cognitive benefit and humorous potential. This will involve choosing from among an interpretation of 'bow' that implies, for example, that the king acknowledged the archer's skilfulness and progress with a reverence ([bav]) and suggests the weirdness of his action, or another implying that the king challenged the archer to show his real progress by giving him a small(er) bow ([bəo]), thus probably hinting his defying and arrogant character.

The interpretative process proceeds along very similar lines with puns relying on homophony, where the concepts involved only share the part of their lexical entries referring to pronunciation. The fact that (11) appears in a headline and refers to a somewhat prototypical scenario - who would not know that steaks are sold in markets? - may activate vigilance. As the audience read the article and learn that two meat producers are merging, hermeneutical vigilance would caution to the ambiguity of the phonological string [sterk] and 
enact sophisticated understanding in order to activate another concept associated to it: STAKE. The plausibility of a new interpretation contingent on this concept is clear: it seems reasonable to reinterpret 'steak' as 'stake' ('investment', 'bet') because the merging reported on is highly risky and costly or would involve a real challenge for the meat market. Since the initial interpretation only provides obvious factual information and, therefore, strengthens encyclopaedic knowledge already stored, vigilance could accept the new interpretation if it senses that more cognitive gain can be obtained from it.

Similarly, the fact that (12) appears in a headline and evokes the title of a Christmas carol could also caution vigilance mechanisms. Hermeneutical vigilance could detect that the journalist might have used 'blight' in order to communicate a different meaning. Engaging in sophisticated understanding results in the activation of (an)other concept(s) with distinct phonological and written forms, logical and encyclopaedic entries: NIGHT and PLIGHT. Vigilance will have to assess the plausibility of interpretations based on them on the basis of costliness and humorous reward. Re-interpretating 'blight' as NIGHT seems reasonable because people with a sore throat cannot surely speak for days, and so does re-interpreting it as PLIGHT because suffering from a sore throat is a tough situation for teachers.

The following figure, based on diagrams by Solska (2012b), illustrates the interpretation of puns. The comprehension module submits an interpretative hypothesis contingent on a concept, as well as estimates about cognitive effects resulting from it, to epistemic vigilance. Upon detecting the plausibility of another interpretation relying on another concept, vigilance triggers sophisticated understanding and the comprehension module constructs an alternative hypothesis. Opting for one or the other hypothesis involves comparing the information in the different entries of each concept and the cognitive gain obtainable: 


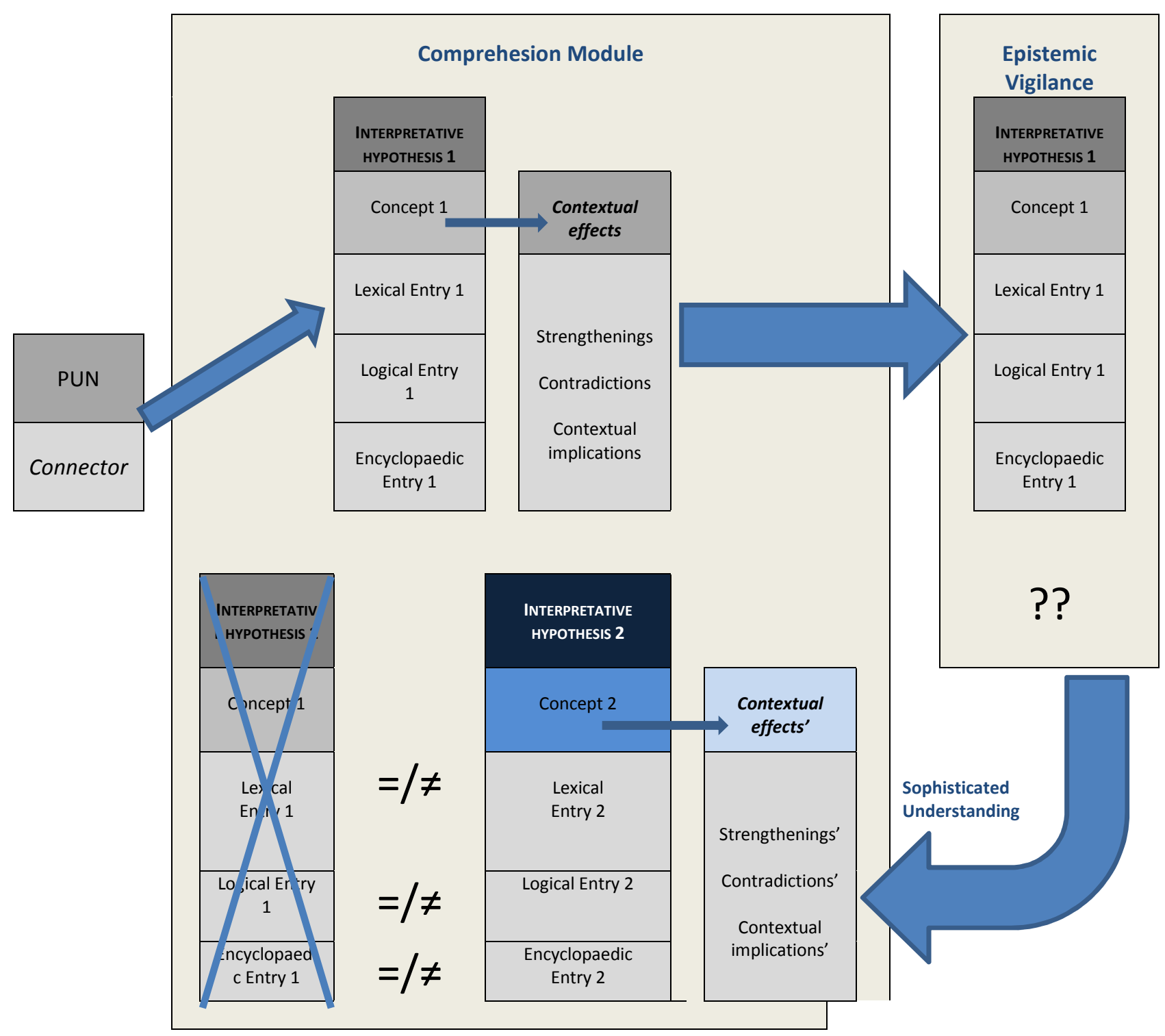

\section{Figure 3: Interpretative process in puns}

Contextual elements alert vigilance mechanisms and these trigger sophisticated understanding. Thanks to this strategy the audience wonder which other interpretation(s) the punster meant and search for it/them in order to solve the lexical puzzle. Sometimes these mechanisms seem powerful and efficient enough to make the audience grant more plausibility and credibility to a second interpretation. This is what happens in single-retention puns, although the first interpretation nonetheless lingers in the audience's mind. Other times, despite the formulation of a new interpretation, these mechanisms fail to choose from among the initial and the new interpretation. They would hence be overrun, overridden or, so to say, 
'defeated' by the cunningness and wittiness of the punster, who has contrived a text and surrounded it by contextual elements that overwhelm them. This is what happens in doubleretention puns and explains why the oscillating effect arises. However, the success of vigilance at disambiguation could depend on personal factors, such as attention level, contextual information available, lack of cognitive frames or richness of lexical repertoire, which may result in failure to activate alternative concepts.

This may have implications for comparing puns. If their quality were to be assessed, double-retention puns could outscore single-retention ones. Failure of vigilance mechanisms to decide upon candidate interpretations might increase the audience's intrigue and desire to solve the linguistic enigma, which could contribute to the lingering and persistence of these puns in their mind. If they subsequently revisited them, they could derive additional weak implicatures, which could provoke some sort of emotional or affective response (Sperber and Wilson 1995; Jodłowiec 2008). Like the punchline in jokes, double-retention puns could generate some cognitive overload because they make a constellation of assumptions weakly manifest, very few of which, if any at all, the audience may be completely aware of. Those assumptions are not fully represented in the audience's mind because they become manifest to them very rapidly, "as if flashing through the back of [their] mind" (Jodłowiec 2008: 79). In terms of funniness or humorous potential, single-retention puns could work better, for vigilance mechanisms are able to discover how the audience were fooled and what exactly made them consider an inappropriate interpretation, which gives them some intellectual satisfaction and pleasure. Nevertheless, funniness also depends crucially on the factors just mentioned, as well as on others like the richness and variety of information connected with the concepts in the pun or the generation of further incongruities and weird scenarios (Jodłowiec 2008). 


\section{Conclusion}

An audience will believe that ambiguous texts like puns may be interpreted differently if they attribute a diverse informative intention to the communicator. This requires theory of mind abilities and a necessary awareness of the communicator's playful or jocular attitude facilitated by vigilance mechanisms, which moves the audience to a position of sceptical trust. This paper has argued that those mechanisms are indispensable for dismissing seemingly relevant interpretations and arriving at less salient ones. On the one hand, epistemic vigilance cautions the audience to the punster's 'malevolence', which becomes evident in a text that biases them to an unintended interpretation. On the other hand, hermeneutical vigilance aids the audience to discover ambiguous strings and how they can be assigned a different reading. This involves backtracking and reanalysis of the text, which is possible if the audience engage in sophisticated understanding.

The proposal presented here goes beyond previous relevance-theoretic accounts of puns, which regard optimal relevance as the criterion determining the acceptability of interpretations and prompting the search for alternative ones. By considering sophisticated understanding, this paper has suggested why backtracking and reanalysis occur. By incorporating the role of vigilance mechanisms, this paper has offered a picture of their processing wherein there is a bidirectional interaction between those mechanisms and the comprehension module. Such interaction needs not occur after interpretative hypotheses are constructed, but while they are under construction, with the comprehension module submitting interpretative hypotheses of chunks or whole utterances/texts to vigilance mechanisms for assessment of their acceptability, and these mechanisms steering the comprehension module to one direction or another. Furthermore, this paper has distinguished between vigilance mechanisms focusing on informants and information and those directed to interpretative skills and their output. 
Future research could examine, for instance, if vigilance mechanisms intervene in the comprehension of idiomatic expressions (Vega Moreno 2007) or utterances requiring meaning reversals (Solska 2012d). In both, the communicator cannot be portrayed as malevolent or having a jocular or playful attitude, so epistemic vigilance would not have to alert the audience to malevolence. However, since she does not intend to communicate the literal meaning of an expression, hermeneutical vigilance could possibly have to grant access to contextual or encyclopaedic information about the expression in question or prompt the comprehension module to bypass its literal meaning. By addressing issues like these, a better appraisal of the role of those mechanisms in a wider variety of linguistic phenomena could be gained. 


\section{Notes}

1. Following a relevance-theoretic convention, reference to the speaker is made through the feminine gender, while reference to the hearer through the masculine.

2. Within false statements Leekam (1991: 160) includes mistakes, lies, jokes, irony, hyperbole, banter, understatement and hypocrisy.

3. The existence of epistemic vigilance mechanisms is supported by research revealing that two- to three-yearold children do not naïvely believe any kind of information, identify inappropriate words, contradict assertions they consider false and prefer individuals they regard as benevolent and competent on the basis of past personal experiences and other people's reports (Clément et al. 2004; Koenig and Harris 2007; Heyman 2008; Corriveau and Harris 2009).

4. Michaelian (2013: 38-43) is sceptical about the frequency wherewith individuals exercise vigilance on the basis of evidence about children and adults' (in)ability to detect deception and attribute trustworthiness relying on factors such as consensus, age of informants, gestures or nervousness.

5. Small caps indicate concepts and stars indicate ad-hoc concepts. 


\section{References}

Apperly, Ian. 2012. Mindreaders. The cognitive basis of "theory of mind". New York: Psychology Press.

Attardo, Salvatore. 1990. The violation of Grice's maxims in jokes. In Kira Hall, Jean Pierre Koenig, Michael Meacham, Sondra Reinman \& Laurel Sutton (eds.), Proceedings of the Sixteenth Annual Meeting of the Berkeley Linguistics Society, 355-362. Berkeley: University of California Press.

Attardo, Salvatore. 1993. Violation of conversational maxims and cooperation: The case of jokes. Journal of Pragmatics 19(6). 537-558.

Attardo, Salvatore. 1994. Linguistic theories of humor. Berlin: Mouton de Gruyter.

Biegajło, Magdalena. 2014. "From which position should I get this joke?!” A relevancedriven joke interpretation: Naïve optimism, cautious optimism, sophisticated understanding? International Studies in Humour 3(1). 2-14.

Bucaria, Chiara. 2004. Lexical and syntactic ambiguity as a source of humor: The case of newspaper headlines. Humor 17(3). 279-309.

Bussman, Hadumod. 1996. Routledge dictionary of language and linguistics. London: Routledge.

Carston, Robyn. 2002: Thoughts and utterances. The pragmatics of explicit communication. Oxford: Blackwell.

Chovanec, Jan. 2005. Czeching out puns and clichés in football reporting. In Jan Chovanec (ed.), Theory and practice in English studies 3, 61-67. Brno: Masarykova Univerzita.

Clément, Fabrice, Melissa Koenig \& Paul Harris. 2004. The ontogeny of trust. Mind \& Language 19(4). 360-379. 
Corriveau, Kathleen \& Paul Harris. 2009. Preschoolers continue to trust a more accurate informant 1 week after exposure to accuracy information. Developmental Science 12(1). 188-193.

Crystal, David. 1995. The Cambridge encyclopaedia of the English language. Cambridge: Cambridge University Press.

Díaz Pérez, Javier. 2012. The use of wordplay in advertisements published in men's magazines. A comparative study in the UK and Spain. Estudios Ingleses de la Universidad Complutense 201. 11-36.

Dynel, Marta. 2010. How do puns bear relevance? In Marta Kisielewska-Krysiuk, Agnieszka Piskorska \& Ewa Wałaszewska (eds.), Relevance studies in Poland. Volume 3. Exploring translation and communication problems, 105-124. Warsaw: Warsaw University Press.

Garcés Conejos, Pilar. 2003. Production, interpretation and garden-path utterances in advertising. In Carlos Inchaurralde \& Celia Florén (eds.), Interaction and cognition in linguistics, 135-144. Frankfurt am Main: Peter Lang.

Giora, Rachel. 1997. Understanding figurative and literal language: The graded salience hypothesis. Cognitive Linguistics 8(3). 183-206.

Guiraud, Pierre. 1976. Les jeux des mots. Paris: Presses Universitaires de France.

Happé, Francesca G. E. 1994. An advanced test of theory of mind: Understanding of story characters' thoughts and feelings by able autistic, mentally handicapped, and normal children and adults. Journal of Autism and Developmental Disorders 24(2). 129-154.

Hartmann, Reinhard R. K. \& F. C. Stork. 1972. Dictionary of language and linguistics. London: Halsted Press.

Heyman, Gail D. 2008. Children's critical thinking when learning from others. Current Directions in Psychological Science 17(5). 344-347.

Jodłowiec, Maria. 2008. What's in the punchline? In Ewa Wałaszewska, Marta Kisielewska- 
Krysiuk, Aniela Korzeniowska \& Małgorzata Grzegorzewska (eds.), Relevant worlds: Current perspectives on language, translation and relevance theory, 67-86. Newcastle: Cambridge Scholars Publishing.

Kasper, Gabriele. 1984. Pragmatic comprehension in learner-native speaker discourse. Language Learning 34(4). 1-20.

Koenig, Melissa \& Paul Harris. 2007: The basis of epistemic truth: Reliable testimony or reliable sources? Episteme 4(3). 264-284.

Kosińska, Katarzyna. 2005. Puns in relevance. In Aniela Korzeniowska and Małglorzata Grzegorzewska (eds.), Relevance studies in Poland. Volume 2, 75-80. Warsaw: Warsaw University Press.

Leekam, Susan R. 1991. Jokes and lies: Children's understanding of intentional falsehood. In Andrew Whiten (ed.), Natural theories of mind. Evolution, development and simulation of everyday mindreading, 159-174. Oxford: Basil Blackwell.

Mascaro, Olivier \& Dan Sperber. 2009. The moral, epistemic, and mindreading components of children's vigilance towards deception. Cognition 112(3). 367-380.

Mazzarella, Diana. 2013. 'Optimal relevance' as a pragmatic criterion: The role of epistemic vigilance. UCL Working Papers in Linguistics 25. 20-45.

Mazzone, Marco. 2011. Schemata and associative processes in pragmatics. Journal of Pragmatics 43(8). 2148-2159.

Mazzone, Marco. 2013. Attention to the speaker. The conscious assessment of utterance interpretations in working memory. Language \& Communication 33(2). 106-114.

McArthur, Tom (ed.). 1992. The Oxford companion to the English language. Oxford: Oxford University Press 
McGhee, Paul. 1972. On the cognitive origins of incongruity humor: Fantasy assimilation versus reality assimilation. In Jeffrey H. Goldstein \& Paul McGhee (eds.), The psychology of humor, 61-80. London: Academic Press.

Michaelian, Kourken. 2013. The evolution of testimony: Receiver vigilance, speaker honesty and the reliability of communication. Episteme 10(1). 37-59.

Norrick, Neal R. 1984. Stock conversational witticisms. Journal of Pragmatics 8(2). 195-209.

Origgi, Gloria. 2013. Epistemic injustice and epistemic trust. Social Epistemology: A Journal of Knowledge, Culture and Policy 26(2). 221-235.

Padilla Cruz, Manuel. 2012. Epistemic vigilance, cautious optimism and sophisticated understanding. Research in Language 10(4). 365-386.

Padilla Cruz, Manuel. 2013a. Metapsychological awareness of comprehension and epistemic vigilance of L2 communication in interlanguage pragmatic development. Journal of Pragmatics 59(A). 117-135.

Padilla Cruz, Manuel. 2013b. Understanding and overcoming pragmatic failure in intercultural communication: From focus on speakers to focus on hearers. International Review of Applied Linguistics in Language Teaching 51(1). 23-54.

Padilla Cruz, Manuel. 2014. Pragmatic failure, epistemic injustice and epistemic vigilance. Language \& Communication 39. 34-50.

Raskin, Victor. 1985. Semantic mechanisms of humor. Dordrecht: Reidel.

Solska, Agnieszka. 2008. The online processing of garden-path utterances: Accessibilitydriven or relevance-driven? In Ewa Wałaszewska, Marta Kisielewska-Krysiuk, Aniela Korzeniowska \& Małgorzata Grzegorzewska (eds.), Relevant worlds: Current perspectives on language, translation and relevance theory, 22-36. Newcastle: Cambridge Scholars Publishing. 
Solska, Agnieszka. 2012a. Relevance-theoretic comprehension procedure and processing multiple meanings in paradigmatic puns. In Agnieska Piskorska \& Ewa Wałaszewska (eds.), Relevance theory. More than understanding, 167-182. New Castle: Cambridge Scholars Publishing.

Solska, Agnieszka. 2012b. The relevance-based model of context in processing puns. Research in Language 10(4). 387-404.

Solska, Agnieszka. 2012c. Appealling and appalling: Puns and degrees of relevance. Paper presented at the $6^{\text {th }}$ Interpreting for Relevance: Discourse and Translation Conference, University of Warsaw, 25-26 September.

Solska, Agnieszka. 2012d. Enforced reversals of meanings: A lexical pragmatic perspective. Paper presented at the $2^{\text {nd }}$ Meaning, Context and Cognition International Conference, University of Łodź, 22-24 March.

Sperber, Dan. 1994. Understanding verbal understanding. In Jean Khalfa (ed.), What is intelligence? 179-198. Cambridge: Cambridge University Press.

Sperber, Dan. 1996. Explaining culture. A naturalistic approach. Oxford: Blackwell.

Sperber, Dan. 2013. Speakers are honest because hearers are vigilant. Reply to Kourken Michaelian. Episteme 10(1). 61-71.

Sperber, Dan \& Deirdre Wilson. 1995. Relevance. Communication and cognition. $2^{\text {nd }}$ edn. Oxford: Blackwell.

Sperber, Dan \& Deirdre Wilson. 1997. The mapping between the mental and the public lexicon. UCL Working Papers in Linguistics 9. 107-125

Sperber, Dan, Fabrice Clément, Christophe Heintz, Olivier Mascaro, Hugo Mercier, Gloria Origgi \& Deirdre Wilson. 2010. Epistemic vigilance. Mind and Language 25(4). 359-393. 
Sullivan, Kate, Ellen Winner \& Natalie Hopfield. 1995. How children tell a lie from a joke: The role of second-order mental state attributions. British Journal of Developmental Psychology 13(2). 191-204.

Sullivan, Kate, Ellen Winner \& Helen Tager-Flugsber. 2003. Can adolescents with Williams syndrome tell the difference between lies and jokes? Developmental Neuropsychology 23(1-2). 85-103.

Tanaka, Keiko. 1992. The pun in advertising: A pragmatic approach. Lingua 87(1-2). 91-102.

Tanaka, Keiko. 1994. Advertising language: A pragmatic approach to advertisements in Britain and Japan. London: Routledge.

Unger, Christoph. 2001. On the cognitive role of genre: A relevance-theoretic perspective. London: University of London dissertation.

Vega Moreno, Rosa E. 2007. Creativity and convention. The pragmatics of everyday figurative speech. Amsterdam: John Benjamins.

Wilson, Deirdre. 1993. Relevance and understanding. Pragmalingüística 1. 335-366.

Wilson, Deirdre. 1997. Linguistic structure and inferential communication. Paper presented at the $16^{\text {th }}$ International Congress of Linguistics, University of Paris, 20-25 July.

Wilson, Deirdre. 1999. Metarepresentation in linguistic communication. UCL Working Papers in Linguistics 11. 127-161.

Wilson, Deirdre. 2011. Understanding and believing. Paper presented at the Relevance Round Table (Meeting 3), University of Warsaw, 27 May.

Wilson, Deirdre. 2013. Irony comprehension: A developmental perspective. Journal of Pragmatics 59(A). 40-56.

Wilson, Deirdre \& Dan Sperber. 1993. Linguistic form and relevance. Lingua 90(1-2). 1-25.

Wilson, Deirdre \& Dan Sperber. 2004. Relevance theory. In Larry Horn and Gregory Ward (eds.), The handbook of pragmatics, 607-632. Oxford: Blackwell. 
Yamaguchi, Haruhiko. 1988. How to pull strings with words. Deceptive violations in the garden-path joke. Journal of Pragmatics 12(3). 323-337.

Yus Ramos, Francisco. 2003. Humour and the search for relevance. Journal of Pragmatics 35(9). 1295-1331.

Yus Ramos, Francisco. 2008. A relevance-theoretic classification of jokes. Łodz Papers in Pragmatics 4(1). 131-157. 